\title{
La deconstrucción del poderío imperial en el siglo IV
}

\author{
Pedro BARCELÓ \\ Universität Potsdam, Alemania \\ barcelo@uni-potsdam.de
}

\section{RESUMEN}

El artículo enfoca desde el punto de vista diacrónico las bases del poderío imperial así como los procesos que durante los siglos IV y V contribuyeron a su paulatina erosión. Mediante una selección de ejemplos se muestra cómo en determinados sectores de la vida pública tales como la administración de la justicia, la dirección del aparato bélico así como la supervisión del culto y sus relaciones con los obispos, los emperadores de esta época van perdiendo de forma progresiva competencias y atribuciones. El punto culminante de esta evolución lo constituye la deposición del emperador de Occidente.

Palabras claves: Bajo Imperio, administración de la justicia, pontifex maximus, magister militum, cristianismo, pérdida de la autoridad imperial.

\section{Die Demontage des Kaisers im vierten Jahrhundert}

\section{ZUSAMMENFASSUNG}

In einer diachronen Perspektive betrachtet dieser Aufsatz die Grundlagen der Kaiserherrschaft im Imperium Romanum und den Prozess, in welchem die Herrscher des späten dritten, vierten und fünften Jahrhunderts schrittweise ihre Autorität einbüßten. Anhand ausgewählter exempla wird aufgezeigt, wie die Delegierung kaiserlicher Kompetenzen und Prärogative in den Bereichen der Administration des Reiches; der Legislative bzw. Judikative (an den praefectus praetorio); des militärischen (Ober-) Kommandos (an die magistri militum) sowie im religiösen Bereich (Aufgabe des Amts als pontifex maximus; Auseinandersetzung mit machtbewussten Bischöfen) zu einem schleichenden Machtverlust führte, den stets weiter gesteigerte Ehrungen und Entrückungen nicht mehr zu kompensieren vermochten. Mit der Aufgabe des hier umrissenen Bündels von Zuständigkeiten und Leistungen büßte das Kaisertum im Westen des Imperium Romanum seine Existenzberechtigung ein.

Schlüsselwor te: Spätantike, Kaiserherrschaft, Imperium Romanum, Verwaltung des Reiches, Rechtsprechung und Legislative, Kriegführung, Heermeister, Oberpontifikat, Christentum, Autoritätsverlust der Kaiser.

Sumario: 1. Bases del poderío imperial en tiempos de crisis, 2. Trasvase de competencias jurisdiccionales, 3. Pérdida de atribuciones militares, 4. Disminución del protagonismo religioso, 5. Ocaso del Imperio occidental. 


\section{Bases del poderío imperial en tiempos de crisis}

Pocos eventos llegaron a conmocionar tan intensamente la radiografía social y política del Imperio romano como la derrota militar y la subsiguiente captura del emperador Valeriano por las tropas persas en el año 260 de nuestra era. ${ }^{1}$

El inaudito suceso, protagonizado por la cabeza visible del orbis terrarum, además de convulsionar la psicología colectiva, aceleró el inicio de un nuevo capítulo de la historia de Roma imprimiéndole un ritmo febril hacia un incierto desenlace. Aunque en el pasado no pocos emperadores habían sucumbido ante sus rivales, ninguno tuvo que sufrir la dolorosa humillación de caer prisionero y terminar su vida en manos de una potencia extranjera.

Es obvio consignar el incalculable impacto de semejante descalabro, sobre todo si consideramos que precisamente aquel que lo protagonizó y sufrió, el propio emperador, era el símbolo de la unidad, continuidad y existencia del Imperio. ${ }^{2}$ Del adecuado ejercicio de su compleja función ejecutiva y mediadora dependía la interacción entre los poderes fácticos (mandos militares, elite senatorial, aristocracias provinciales y locales, etc.), así como la legitimación del secular equilibrio reinante entre los representantes del Estado y el más allá, que en opinión de los contemporáneos constituía un decisivo soporte para la pervivencia del orden establecido.

Éxitos y victorias militares fueron percibidos desde siempre como pruebas de aceptación del régimen de turno por parte de los poderes sobrenaturales. ${ }^{3}$ En este contexto las peripecias de Valeriano aparte de debilitar los vínculos que enlazaban el Estado con sus protectores divinos, conllevaron una alteración de su simetría social. Una sensación de inseguridad e impotencia frente a las incertidumbres del devenir se apoderó temporalmente de las élites dominantes que no acertaban a encontrar respuestas adecuadas a los apremiantes desafios, como certifican los años que siguen a la catástrofe del cautivo princeps, considerados generalmente como los más desafortunados de la historia de Roma. ${ }^{4}$

${ }^{1}$ Disponemos de varias versiones sobre las consecuencias de este crucial episodio. La visión persa esta plasmada en una inscripción monumental dedicada al vencedor rey persa Sapor I, véase M. BACK, Die Sassanidischen Staatsinschriften, Leiden 1978, 306-314. En su historia adversus paganos 7, 22, 3-4 el cronista cristiano Orosio considera el destino del perseguidor de cristianos Valeriano como un merecido castigo divino. Otro enfoque de orientación pagana lo proporciona un texto recogido en el 13 oráculo sibilino, donde se minimaliza la responsabilidad del emperador y se ensalza la posterior actuación de Odenato, celebrado como restituidor del poderío romano en Oriente, véase D. S. PotTer, Prophecy and History in the Crisis of the Roman Empire. A Historical Commentary on the Thirteenth Sibyline Oracle, Oxford 1990, 155-164. Sobre la repercusión de la derrota de Valeriano en la historiografía tardía y en los historiadores bizantinos véase B. Bleckmann, Die Reichskrise des III. Jahnrhunderts in der spätantiken und byzantinischen Geschichtsschriebung. Untersuchungen zu den nachdionischen Quellen der Chronik des Johannes Zonaras, Munich 1991, 97-129.

2 W. KunоғF, Herrschertum und Reichskrise. Die Regierungszeit der römischen Kaiser Valerianus und Gallienus (253-268 n. Chr.), Bochum 1979, 9-26.

3 Véase al respecto el material recogido en J. R. Fears, Princeps a diis electus. The Divine Election of the Emperor as a Political Concept at Rome, Roma 1977; M.W. Graham, "Divine Protection of Frontiers", en: News and Frontiers Consciousness in the Late Roman Empire, Ann Arbor 2006, 149-154.

4 G. Alföldy, Die Krise des Römischen Reiches. Geschichte, Geschichtsschreibung und Geschichtsbetrachtung. Ausgewählte Beiträge, Stuttgart 1989, así como la posición escéptica de K. Strobel, Das Imperium Romanum im 3. Jahrhundert. Modell einer historischen Krise? Zur Frage 
No obstante debemos ser sumamente cautos a la hora de emitir valoraciones comparativas. El elogio de Elio Arístides al Imperio, pronunciado unas generaciones antes causa la sensación de referirse a un contexto totalmente antitético en relación con el que acabamos de comentar, cuando resalta:

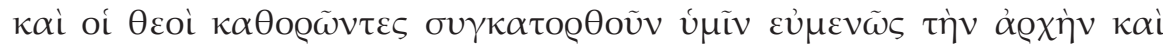

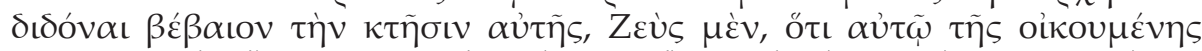

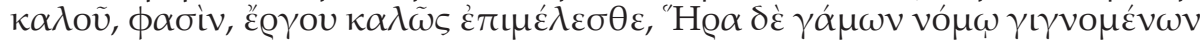

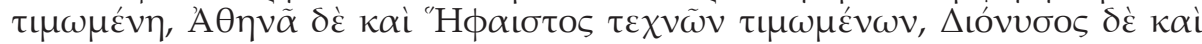

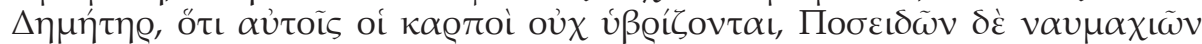

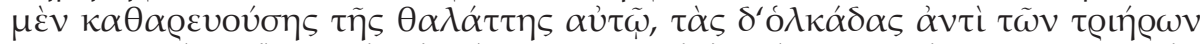

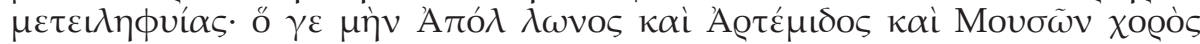

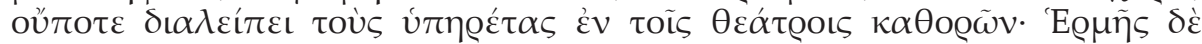

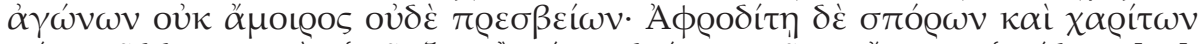

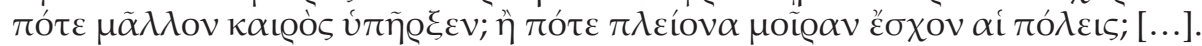

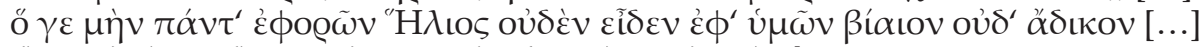

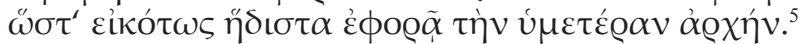

Nadie negará que desde una óptica posterior, la entusiasta evocación de unos tiempos supuestamente felices en los que imperaba la paz, la armonía y el bienestar parece reflejar una realidad bien distinta de la que reinaba en el último tercio del siglo III. Pero si abandonamos la esfera de la literatura y nos centramos en el análisis histórico, el bucólico panorama de un mundo pleno de brillantes colores adquiere un tinte más bien gris. Probablemente la era de Elio Arístides distaba bastante de ser tan idílica como apuntan sus sugestivas metáforas y, posiblemente, los tiempos de Valeriano fueron menos sombríos de lo que a primera vista pudiera parecer. ${ }^{6}$

Sin duda perduraban serios problemas que amenazaban la integridad y la cohesión del Imperio, si pensamos en los conatos segregacionistas de las provincias galas, en

mentaler Strukturen breiter Bevölkerungsschichten in der Zeit von Marc Aurel bis zum Ausgang des 3. Jh. n. Chr., Stuttgart 1993, 185-348 que pone en duda la existencia de una conciencia de crisis en el siglo III.

5 Elio Arístides, A Roma 104 ss. “...y que los dioses, contemplándolo todo desde arriba, en su benevolencia dirigen bien el Imperio junto con vosotros, y han confirmado vuestra posesión del mismo: Zeus, porque cuidáis bien de su bella obra, según se dice, ecúmene; Hera, que es honrada porque los matrimonios tienen lugar bajo el imperio de la ley; Atena y Hefesto, por la estima en que son tenidas las artes; Dionisio y Deméter, puesto que sus frutos no son deshonrados; Posidón, puesto que su mar está limpio de batallas navales y ha trocado las trirremes por navíos de carga. Los coros de Apolo, Ártemis y las Musas nunca dejan de ver a sus sirvientes en los teatros. Hermes no carece ni de juegos ni de embajadas y Afrodita no carece ni de simientes ni de gracias. ¿Cuándo hubo un momentos más favorables, o cuándo las ciudades tuvieron una mayor porción de estas bendiciones? [...] Helio, que todo lo observa no ha visto junto a vosotros ningún acto ni violento... de manera que con razón observa complacido vuestro Imperio.” Traducción castellana de J. M. CORTÉs COPETE, Elio Aristídes, Discurso a Roma, Madrid, Gredos, 1997. Véase también el comentario de R. KLeIN, Die Romrede des Aelius Aristides: Einführung, Darmstadt 1981; S. A. SterTz, “Aelius Arsitides' Political Ideas", en: ANRW II 34, 2 (1993) 1248-1270.

6 Sobre el panorama político y social de la época de los Antoninos véase P. Brown, Die letzten Heiden. Eine kleine Geschichte der Spätantike, Berlin 1978, 31-86. Por otra parte las consecuencias de la derrota de Valeriano para las provincias orientales fueron menos catastróficas de lo que se hubiera podido esperar, véase M. SOMmER, Die Soldatenkaiser, Darmstadt 2004, 51. 
el independentismo de Palmira, en la periódica amenaza de las fronteras renanas y danubianas o en las incesantes usurpaciones y guerras internas ${ }^{7}$, pero no es menos cierto que en el punto álgido de la crisis aparecen periódicamente personajes en el trono del Imperio tales como Claudio Gótico (268-270), Aureliano (270-275) o Probo (276-282) capaces de aportar soluciones. ${ }^{8}$ Con ello se evidencia una vez más que el potencial resolutivo del Estado dependía en buena parte de su primer mandatario, de sus habilidades y de su fortuna. En este sentido la repentina desaparición de Valeriano se configuraba como un hecho tan trágico como a la vez irrepetible.

¿Como sería posible identificarse en el futuro con un régimen cuyo máximo representante había demostrado de forma tan drástica su ineficacia? El ejemplo de Valeriano quedaba lejos de la pugna por el trono librada entre las paredes del palacio o en los campos de batalla frente a competidores internos ya que manifestaba un explosivo grado de deterioro de la autoridad imperial, aumentando su proyección negativa hacia el exterior en una medida hasta entonces desconocida.

Este último aspecto puede ser ilustrado a través de la ascensión al trono de Diocleciano (284-305), acontecida después de la fortuita muerte de Caro durante el sitio de la capital persa Ctesifonte y del posterior asesinato de su hijo y sucesor Numeriano, presumiblemente víctima de un complot instigado por el praefectus praetorio Aper (284). ${ }^{9}$ La escena que sigue a la reunión de la plana mayor del ejército que conllevará la elección de Diocleciano es de una rudeza difícil de superar. El recién proclamado emperador apuñala con sus propias manos a Aper ante la perplejidad de las tropas congregadas para celebrar su elevación al trono. Esta sangrienta primera medida del nuevo gobierno intentará ser atenuada por la posterior literatura apologética mediante un juego de palabras oracular puesto en boca de un druida que había profetizado a Dioleciano su subida al trono, si antes conseguía abatir personalmente a un jabalí (aper). ${ }^{10}$

A pesar de todos los intentos de explicación, la sombría sucesión de hechos en torno a la proclamación de Diocleciano no contribuía a reforzar la confianza en la cúpula de un Imperio que, a través de semejante puesta en escena, se desacreditaba irremediablemente. Los emperadores que en la segunda mitad del siglo III se sucedieron de forma vertiginosa y violenta distaban mucho de poder ser considerados como una muestra de ejemplaridad y de solidez. El desprestigio que acumulaban muchos de ellos se contagiaba a las instituciones que representaban. Ambiciones insaciables, intrigas, violencia indiscriminada así como ineficacia administrativa y militar estaban al orden del día. ${ }^{11}$

7 Sobre las décadas de los años sesenta y setenta del siglo III véase L. DE BLOIS, The policy of the Emperor Gallienus, Leiden 1976; A. Watson, Aurelian and the Third Century, Londres 1999.

${ }^{8}$ M. SOMMER, Soldatenkaiser, 54-66.

9 H. W. BIRD, "Diocletian and the Deaths of Carus, Numerian and Carinus", Latomus 35 (1976) 123-132.

10 P. Barceló, "Diocletian”, en: M. Clauss (ed.), Die römischen Kaiser. 55 historische Portraits von Caesar bis Justinian, Munich 1997, 259 s.; W. KuHoff, Diokletian und die Epoche der Tetrarchie, Frankfurt 2001, $22 \mathrm{~s}$.

11 A. Demand, Die Spätantike, Munich 1988, 38-45 
Lo verdaderamente notable en este contexto es la firme voluntad de Diocleciano, cuya elevación al trono había sido tan poco halagüeña ${ }^{12}$, de acabar de una vez para siempre con la desesperante situación. Toda su futura política estará encaminada a poner coto al desorden, a sistematizar el ejercicio del poder y a reformar el tejido económico, social y religioso del Imperio. ${ }^{13} \mathrm{El}$ anhelo de lograr estabilidad, de hacer prevalecer un cúmulo de regulaciones innovadoras y de terminar con el caos que abatía la vida pública es el detonante de la gestión de Diocleciano que culminará en la creación de la Tetrarquía, símbolo de una nueva forma de gobierno concebida como respuesta a las deficiencias del pasado. A través de la renuncia voluntaria a la monocracia y la subsiguiente puesta en vigor de un sistema de pluralidad monárquica se pretendía acometer no sólo una profunda reforma de las instituciones, sino promover un modelo de estado compartido, racional y exitoso. ${ }^{14}$

¿Fue el sistema tetrárquico, con sus defectos y virtudes, una solución para salir simplemente del paso o fue más allá? Estas preguntas no sólo las formulaban los contemporáneos, sino que las podemos plantear aquí por igual para detectar las líneas maestras del ejercicio del poder imperial durante el Bajo Imperio, cuyas competencias, funciones y alcance nunca han sido definidas con anterioridad.

Visto de un modo retrospectivo, las modalidades del ejercicio del poder imperial eran fruto de un dilatado proceso de concentración de competencias que se había iniciado con la instauración del Principado. Desde que Augusto fuera investido de las funciones de comandante en jefe del ejército (imperium proconsulare maius), de juez supremo (iudex) y de supervisor del culto (pontifex maximus) se había generado un módulo de gobierno basado en la acumulación de magistraturas, dignidades, recursos y prestigo sin parangón en la historia de Roma. ${ }^{15} \mathrm{La}$ asunción sincrónica de diversas potestades por parte de un sólo individuo es la línea diferencial que separa la República del Principado. Mediante una elaborada mezcla de personalización e institucionalización se proyecta un nuevo diseño de Estado que no gravitará, como en el pasado, en torno a la aristocracia senatorial, sino que se asentará sobre la capacidad resolutiva del princeps. La manera de manejar coordinadamente la multiplicidad de sus atribuciones marcará el estilo de gobierno de los sucesores de Augusto. ${ }^{16}$

En este sentido, la autoridad de los emperadores residía en su habilidad de saber actualizar y adaptar en la dosis adecuada los resortes de poder disponibles a los problemas que surgían. Cuando un princeps fracasaba en este empeño, o perdía el control sobre una de sus vitales prerrogativas, corría el riesgo de ser destronado. Por esta razón el ejercicio conjunto de sus competencias militares, judiciales y religiosas constituía el signo de identidad de su gobierno. Si esta facultad de ejercicio caía en

${ }^{12}$ M. SOMMER, Soldatenkaiser, 68.

13 Sobre las metas y realizaciones de la Tetrarquía véase A. Demand, Die Spätantike, 49-61; W. Kunoff, Diokletian und die Epoche der Tetrarchie, 246-297, 327-564.

${ }_{14}$ F. KolB, Diocletian und die Erste Tetrarchie. Improvisation oder Experiment in der Organisation monarchischer Herrschaft, Berlin, Nueva York 1987, 10 ss.

15 Sobre el carácter integrador del modelo de gobierno ideado por Augusto véase F. JAcQues, J. ScheID, Rom und das Reich in der Hohen Kaiserzeit 44 v. Chr.-260 n. Chr., vol. 1: Die Struktur des Reiches, Stuttgart, Leipzig 1998, 1-119.

16 J. Bleicken, Verfassungs- und Sozialgeschichte des Römischen Kaiserreiches, vol. 1, Paderborn $1978,112-125$. 
desuso no sólo se podía acelerar la degradación de la autoridad imperial, sino que se ponía igualmente en entredicho la viabilidad de todo el sistema. ${ }^{17}$ Dado que el proceso de deterioro de la autoridad de los emperadores, que arranca en el siglo III y se agudiza a partir del siglo $\mathrm{V}$, es un hecho notorio, procede investigar los motivos que contribuyeron a tal situación. ¿Fue la agonía del poder imperial ante todo consecuencia de las incursiones de pueblos germánicos o existen paralelamente otros elementos dignos de ser tenidos en cuenta? Las siguientes reflexiones intentan dar algunas respuestas a esta clase de interrogantes.

\section{Trasvase de competencias jurisdiccionales}

Como podremos observar a través de los ejemplos que a continuación comentare$\operatorname{mos}^{18}$, la disminuición del poderío imperial no tendrá lugar de forma abrupta, sino más bien mediante un dilatado proceso de erosión que se inicia en la era postetrárquica y se prolonga hasta la segunda mitad del siglo $\mathrm{V}$ y en cuyo centro se situa el pulso desatado en torno a las atribuciones judiciales, militares y sacras del emperador.

Empecemos este cometido analizando las tareas judiciales del princeps, prestando especial atención a su participación directa en la impartición de la justicia.

A raíz de la creación de la Tetrarquía se habían introducido notables modificaciones administrativas en la cúpula del Imperio que regulaban las competencias del praefectus praetorio. ${ }^{19}$ Este emblemático cargo, definido hasta entonces por su mando sobre tropas de élite (guardia pretoriana) y su cercanía al emperador, dejará de desempeñar sus ancestrales funciones militares para convertirse en la más alta magistratura civil. De esta manera sus titulares pasarán a ser depositarios de las máximas atribuciones judiciales. De hecho la facultad de decidir contenciosos en última instancia, desde siempre una de las clásicas fuentes de la autoridad imperial, le será otorgada al praefectus praetorio cuyos veredictos no podrán ser apelados, ni incluso ante el emperador. ${ }^{20} \mathrm{~A}$ través de la delegación de su suma potestad judicativa en sus lugartenientes, los emperadores de finales del siglo IV contribuirán, más o menos conscientemente, a la debilitación de su propia posición. Disponemos de un valioso y casi desconocido testimonio que nos proporciona Amiano Marcelino al respecto en el que se alude a esta transferencia de poderes mediante los siguientes argumentos:

${ }_{17}$ Acerca de la importancia del princeps en el manejo de los hilos del poder imperial véase F. MiLlar, The Emperor in the Roman World, Londres 1992.

18 Debemos resaltar que se trata de una breve selección de informaciones, representativas si cabe, pero de ninguna manera exhaustivas. Hasta ahora aun no han sido analizadas sistemáticamente todas las fuentes disponibles al respecto.

${ }^{19}$ Véase al respecto A. Gutsfeld, "Der Praetorianerpräfekt und der kaiserliche Hof im 4. Jahrhundert n. Chr.", en: A. Winterling (ed.), Comitatus. Beiträge zur Erforschung des spätantiken Kaiserhofes, Berlin 1998, 75-102; C. Kelly, "Empire Building", en: G. W. Bowersock, P. Brown, O. Grabar (eds.), Interpreting Late Antiquity. Essays on the Postclassical World, Cambridge (Massachusetts) 2001, 170195.

${ }^{20}$ Codex Theodosianus 11, 30, 16. 
infra imperiale columen causarum essente minutiae priuatarum, ille ad humilitandam celsitudinem potestatis negotiorum examina spectanda instituisse arbitratus, ut monebat, abstinuit penitus laxauitque rapinarum fores, quae roborabantur in dies iudicum aduocatorumque prauitate sentientium paria, qui tenuiorum negotia militaris rei rectoribus uel intra palatium ualidis uenditantes aut opes aut honores quaesiuere praeclaros. $^{21}$

Según el historiador antioqueno el praefectus praetorio Modesto disuadió al emperador Valente (364-378) de seguir en el futuro compareciendo ante los tribunales, aduciendo que, en vista de las menudencias que allí se dirimían, el ejercicio de las tareas forenses mancillaba la majestad del primer hombre del Estado. No carece de interés la valoración negativa que da Amiano al episodio. Según nuestra fuente, el desplazamiento del princeps desde el centro de la administración de la justicia, lejos de mejorar la situación, contribuyó en términos generales a aumentar el descontento y la corrupción y, con ello, al desprestigio del gobierno.

Si ponemos en nuestro punto de mira las atribuciones desempeñadas hasta entonces por el emperador observamos que en la medida en que éste pierde o renuncia a competencias enmarcadas en el ámbito civil, que a partir de cierto momento serán monopolizadas por otros, aumenta la necesidad de redefinir su liderazgo.

\section{Pérdida de atribuciones militares}

En el Bajo Imperio las prerrogativas militares del emperador eran más determinantes que nunca. Hacía tiempo que su gobierno había dejado de apoyarse en el consenso de la aristocracia senatorial, pasando a depender, ante todo, del favor del ejército. ${ }^{22}$ El emperador de turno, comandante en jefe de las fuerzas armadas, sólo podía mantenerse en su cargo ejerciendo el imperium, es decir, tomando personalmente en última instancia las decisiones pertinentes en materia bélica. Muy conscientes de ello, los emperadores del siglo IV se desenvuelven preferentemente en el ámbito castrense: aparecen rodeados de sus soldados efectuando nombramientos, otorgando ascensos a

21 Amiano Marcelino 30, 4, 2: "Tenía una expresión forzada y engañosa, y aseguraba que las minucias de los jucios de los particulares no eran apropiadas para la majestad del imperio. Por su parte, Valente creyendo que, como Modesto le aseguraba, el examen de los casos privados servirían tan sólo para rebajar su dignidad, se abstuvo completamente de ellos, con lo cual dejó abiertas las puertas para que cada vez fueran cometiéndose más robos. A esto ayudaba también la maldad de los jueces y abogados, que estaban unidos en esta cuestión debido a su común afán por conseguir riquezas y grandes honores juzgando los casos de las personas humildes en función de los intereses de los mandos militares o de las gentes poderosas del palacio.” Traducción castellana de M. L. Harto TrujILlo, Amiano Marcelino, Historia, Madrid, Akal, 2002.

22 Sobre la función del ejército en época tardoimperial véase G. Alföldy, Das Heer in der Sozialstruktur des römischen Kaiserreiches, en: G. Alföldy, Römische Heeresgeschichte, Beiträge 1962-1985, Amsterdam 1987, 26-609; A. Demandt, Die Spätantike, 255-272; Y. Le Bohec, L’armée romaine sous le Haute-Empire, Paris 1990. 
oficiales destacados, planeando y dirigiendo directamente las operaciones, celebrando triunfos sobre sus enemigos. ${ }^{23}$

Las biografías de Constantino (306-337), Constancio II (324-361), Valentiniano (364-375) o Teodosio (379-395) nos suministran un cúmulo de ejemplos acerca de la implicación de cada uno en tareas militares de toda índole. Aquellos emperadores que suscitaron la oposición de la oficialidad, como sucedió en el caso concreto de la revuelta desencadenada contra Constante (350), pagaron un alto precio por alejarse de la tropa y desentenderse de sus obligaciones militares. ${ }^{24}$

El permanente cultivo de las relaciones con el estamento militar, así como un intenso contacto con la plana mayor del ejército, constituía la más sólida garantía de supervivencia. Este aspecto puede ser ilustrado a través del comportamiento de Constancio II. Este emperador, que junto a Augusto fue el que reinó más tiempo que ningún otro, condujo personalmente una y otra vez a sus tropas a la frontera del Eufrates a fin de combatir contra el Imperio Persa, hecho que le permitió adquirir un alto grado de compenetración con el ejército estacionado en Oriente. También operó reiteradamente con las legiones destacadas en las orillas del Danubio y del Rhin contra los sármatas, godos, alamanos y francos, lo que le acercó al ejército occidental. Constancio II adoptó personalmente un sinfín de iniciativas en materia militar. Proyectó y dirigió personalmente múltiples campañas, nombró o destituyó a numerosos mandos, castigó infracciones y recompensó servicios prestados. La oficialidad de su ejército le mantuvo la fidelidad en tiempos de crisis. Sus soldados, acostumbrados a su atinada forma de ejercer el mando, apoyaron su quehacer. Nunca se negaron a obedecerle. ${ }^{25}$

Dentro de este contexto el año 387 marcará un hito en la historia militar del Imperio. Por aquel entonces Arbogasto, destacado oficial de la élite militar germánica al servicio de Roma, obtuvo la dignidad de magister militum, es decir, el máximo cargo operativo del ejército. Lo sorprendente del caso es que este nombramiento aconteció sin que el emperador fuera previamente consultado y diera posteriormente su aprobación. Fue la misma cúpula militar, apoyada por la tropa, la que prescindiendo de su comandante en jefe, elevaba a uno de sus miembros a la cumbre del organigrama militar, haciendo del emperador un mero espectador ${ }^{26}$ Con ello no sólo se acentuaba la existencia de un foco de decisión paralelo a la corte imperial, sino que se ponía públicamente de manifiesto el deterioro de autoridad del primer mandatario del Estado.

En la medida en que el emperador quedaba relevado del ejercicio de sus prerrogativas militares que desde la época de Augusto habían constituido el factor primordial de su mandato, aumentaba la influencia política de aquellos que se las atribuían. Será decisivo el protagonismo de un creciente número de magistri militum, tales como

${ }^{23}$ M. WhitBy, "Emperors and Armies, AD 235-395”, en: S. Swain, M. Edwards (eds.), Approaching Late Antiquity. The Transformation from Early to Late Empire, Oxford 2004, 156-158.

${ }_{24}$ Aurelio Victor 41, 23; Eutropio 10, 9, 3. A. Снаuvot, Opinions romaines face aux barbares au IVe siècle ap. J.- C., Paris 1998, $156 \mathrm{~s}$.

25 P. Barceló, Constantius II. und seine Zeit. Die Anfänge des Staatskirchentums, Stuttgart 2004, $189 \mathrm{~s}$.

26 P. Grattarola, "La morte dell'imperatore Valentiniano II", RIL (1979) 359-370; E. Flaig, "Für eine Konzeptionalisierung der Usurpation im Spätrömischen Reich", en: F. Paschoud, J. Szidat (eds.), Usurpationen in der Spätantike, Stuttgart 1997, 21 ss. 
Arbogasto, Merobaudes, Ricimero, Aetio o Estilicón ${ }^{27}$, que asumirán de facto la dirección del Imperio relegando en cada caso a los emperadores a un segundo plano. ${ }^{28}$ A pesar de ello no llega a consumarse un vacío de poder, pero sí un trasvase de competencias en detrimento del emperador. Al quedar este último cada vez más aislado de su dispositivo militar, perdía su capacidad de acción quedando reducido a un entorno político, económico y social cada vez más exiguo. Desde la fase final del siglo IV el dominio militar efectivo de los emperadores que administraban las provincias occidentales del Imperio se fue reduciendo paulatinamente hasta límites nunca antes imaginados. Al perder el control sobre el ejército, su autoridad tendía a convertirse en un mero formalismo.

Para percatarnos de hasta qué punto el modo de proceder de Arbogasto consiguió quebrar una tradición secular, basta observar una escena acaecida dentro de los muros del palacio. Arbogasto no tuvo reparo en matar en el consistorio a un favorito del emperador que, consciente del peligro que le acechaba, había buscado amparo bajo la púrpura imperial. De nada le sirvió. A continuación, y ante la consternación de los cortesanos, Arbogasto hizo pedazos la orden de destitución firmada por el mismo Valentiniano II (375-392). ${ }^{29}$ Mientras el magister militum continuó en su puesto, el humillado emperador debía temer por su vida. No tardaría en ser eliminado por Arbogasto que, a su vez, nombrará un emperador de su agrado para sucederle: Eugenio.

El vital protagonismo que logrará acumular Arbogasto queda confirmado por una mención del historiador eclesiástico Orosio que refiriéndose a su desbordante personalidad anota:

ipse acturus imperium vir barbarus, animo consilio manu audacia potentiaque ni-
mius. ${ }^{30}$

Otra de las más claras alusiones al debilitamiento del poder imperial la encontramos en el panegírico dedicado al emperador Antemio (467-472) confeccionado por

${ }_{27}$ Véase por citar un solo ejemplo el elogio a Estilicón de la pluma de Claudiano que eleva al magister militum a la altura de un emperador: discrimine Roma supremo/ inter supplicium populi deforme pependit;/et tantum Libyam fructu maiore recepit/ quam peperit, quantum graviorem amissa dolorem/ quam necdum quaesita movent. quis Punica gesta, / quis vos, Scipiadae, quis te iam, Regule, nosset,/ quis lentum caneret Fabium, si iure perempto/insultaret atrox famula Carthagine Maurus?/ haec omnes veterum revocavit adorea lauros;/ restituit Stilicho cunctos tibi, Roma, triumphos. "En este último peligro estuvo en suspenso el destino de Roma en medio del horroroso sufrimiento de su pueblo; la recuperación de Libia fue de mayor provecho que la primera conquista, en la medida en que las cosas perdidas provocan un dolor más profundo que las que todavía no se han poseído. ¿Quien conocería las Guerras Púnicas, quien a vosotros Escipiones; quien se acordaría ya de tí Régulo; quien cantaría al prudente Fabio, si el espantoso mauro, tras abolir nuestros derechos, saltara sobre una Cartago a él sometida? Esta victoria ha hecho revivir todos los laureles de nuestros viejos héroes; Estilicón te ha restituido, oh Roma, todos tus triunfos" (De Consulatu Stilichonis I 376-385).

28 J. Martin, Spätantike und Völkerwanderung, Munich 1987, 36 s.; A. Demandt, Die Spätantike, $261 \mathrm{~s}$.

29 A. Demand, Die Spätantike, 134.

30 Orosio, historia adversus paganos $7,35,11$ : “...ya que era él mismo en realidad el que iba a llevar las riendas del poder, él, un hombre bárbaro, pero sobrado de espíritu, de buen sentido, de fuerza, de audacia y de poder...". Traducción castellana de J. E. SÁnchez SAlor, Orosio, Historias, Madrid, Gredos, 1982. 
Sidonio Apolinar. El obispo galo, que intentaba en vano oponerse a los visigodos de Eurico en vista de una previsible defección de las provincias galas de la autoridad imperial, especifica las obligaciones militares del primer hombre del Estado de la siguiente manera:

\section{modo principe nobis}

est opus armato, veterum qui more parentum

non mandet sed bella gerat, quem signa moventem

terra vel unda tremant, ut tandem iure recepto

Romula desuetas moderentur classica classes $^{31}$

Tales exigencias expresadas en el tono de una arenga más que de una proclama, reflejan una situación política altamente deteriorada. Tampoco pueden disimular el hecho que la construida imagen del emperador guerrero se agote en la evocación de una mera figura retórica totalmente desligada de la realidad.

\section{Disminuición del protagonismo religioso}

Si el despojo de las atribuciones militares del emperador comporta un debilitamiento sin precedentes, a largo plazo no será menos la disminución de las ancestrales funciones imperiales en el campo de la religión. Desde la época de Augusto la supervisión del sensible engranaje político-social-cultual del Imperio pasará a ser competencia de los emperadores que, a través de su dignidad pontifical, controlarán el culto y harán de él un pedestal de su siempre discutida legitimidad. Cada princeps sin excepción en función de sus múltiples cargos sacerdotales participaba activamente en las celebraciones que imponía el permeable y elástico sistema politeista. En su calidad de pontifex maximus obraba como una especie de gestor de la política religiosa, legislando en materia sacra y emitiendo veredictos sobre toda clase de temas relacionados con la organización del culto estatal..$^{32}$ De él dependía en buen grado el fomento de nuevas divinidades (Heliogábalo-Baal de Emesa, Aureliano-Sol Invictus, Constantino-Cristo) o el rechazo (Augusto-Isis, Valeriano-cristianismo, Diocleciano-maniqueísmo,) de aquellos cultos que pretendiesen establecerse en suelo romano. ${ }^{33}$

31 Sidonio, carm. 2, 382-386: "Actualmente necesitamos un emperador guerrero, que siguiendo la costumbre de nuestros antepasados no solo encargue sino que dirija las campañas; uno a quien teman tierra y mar en cuanto mueva sus insignias de modo que el grito de guerra romano, recobrado su poderío, guíe nuestras armadas desacostumbradas a la lucha." Véase tambien Sidonio Apolinar, carm. 7, 550556.

32 Sobre las competencias sacerdotales del emperador véase el catálogo confeccionado por R. Stepper, Augustus et sacerdos. Untersuchungen zum römischen Kaiser als Priester, Potsdamer Altertumswissenschaftliche Beiträge 9 (2003).

${ }_{33}$ P. BARCeló, "Die Macht des Kaisers- Die Macht Gottes: Alleinherrschaft und Monotheismus in der römischen Kaiserzeit”, en: P. Barceló (ed.), Contra quis ferat arma deos? Vier Augsburger Vorträge zur Religionsgeschichte der römischen Kaiserzeit, Munich 1996, 84-100; P. BARCELó, "Monoteísmo y monarquía en el Imperio romano", en: C. Rabassa, R. Stepper (eds.), Imperios sacros, monarquías divinas, Publicacions de la Universitat Jaume I, Castellón 2002, 17-37. 
Las preferencias del emperador, es decir, su relación personal con una divinidad concreta, ocuparán un plano primordial al momento de plantear las directrices de la política religiosa. El criterio imperante era la reciprocidad. El interesado ensalzaba a una determinada deidad que, a su vez, proporcionaba a su gobierno un aura de esplendor divino. Esta constatación es indispensable para entender el modelo tetrárquico basado en premisas tradicionalistas y politeístas. Por eso los tetrarcas no podían tolerar una actitud de rechazo al orden divino que ellos representaban, como tampoco aceptaban las pretensiones del dios cristiano de monopolizar el olimpo de los dioses. De ahí que la persecución del cristianismo fuera una parte integral de su ideario político. En estas circunstancias, la profesión del politeísmo se convertía en una declaración de principios y en el símbolo de la Tetrarquía, cuyo sistema de gobierno aparecería avalado por un sugerente modelo de pluralidad y partición del poder. Diocleciano, Maximiano, Constancio y Galerio actuaban al igual que Júpiter, Hércules, Marte y los otros dioses en un plano de igualdad que se veía cuestionado por la esencia monoteísta del cristianismo. ${ }^{34}$

El panorama político y religioso del Imperio se transformaría radicalmente con la irrupción de un dios monoteísta y excluyente, episodio paralelo al derrumbamiento de la Tetrarquía. ${ }^{35}$ Ningún otro fenómeno adquirirá tanta relevancia para el futuro del Imperio como la expansión y la consolidación del cristianismo. ${ }^{36}$ Constantino y sus sucesores, de acuerdo con una ingente jerarquía clerical que incrementaba con asombrosa celeridad sus recursos y su presencia social, sentarán las bases de una nueva relación entre la Iglesia y el Estado conmoviendo los cimientos de la milenaria tradición romana. No será el emperador, sino la teología cristiana la que formulará en el futuro la postura religiosa a seguir. ${ }^{37}$

Lo que hasta ahora era un hecho indiscutible, es decir: la ubicación del emperador en el centro del culto, empezará a tambalearse. Mientras que los antecesores de Constantino habían ocupado un lugar preferente en el complejo entresijo de relaciones cultuales que garantizaban el orden político y social del Estado, los sucesores de Constantino se verán desplazados paulatinamente a su periferia. ${ }^{38}$

${ }^{34}$ F. Kolb, Diocletian und die Erste Tetrarchie, 88 ss.

35 P. BARCELó, "Konstantins Bekehrung zum Christentum", Historicum. Zeitschrift für Geschichte 2008, 32-41.

${ }^{36}$ E. Herrmann-Otto, Konstantin der Große, Darmstadt 2007, 48 ss.

${ }^{37}$ P. BARCELÓ, "Zur Begegnung, Konfrontation und Symbiose von religio Romana und Christentum", en: G. Gottlieb, P. Barceló (eds.), Christen und Heiden in Staat und Gesellschaft des zweiten bis vierten Jahrhunderts. Gedanken und Thesen zu einem schwierigen Verhältnis, Munich 1992, 178-191.

38 Graciano había renunciado a su dignidad pontifical y Teodosio será el primer emperador que después de su proclamación ya no asumirá el título de pontifex maximus. El traslado de Teodosio a instancias del obispo de Milán Ambrosio del apsis de la Iglesia, reservada a la jerarquía clerical a las gradas dedicadas a los fieles es posiblemente la imagen más emblemática de este desplazamiento. Teodoreto, Historia de la Iglesia 5 18, 20 s. transmite el episodio de la siguiente manera (Theodoretus, Kirchengeschichte, 2 ed.”, L. Parmentier y F. Scheidweiler eds., Berlin: Akademie-Verlag [Die

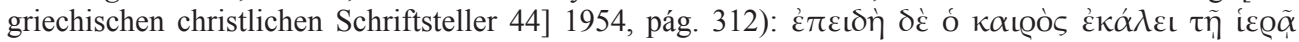

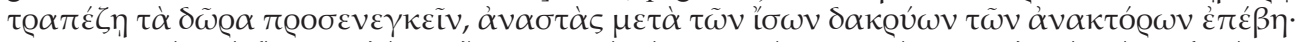

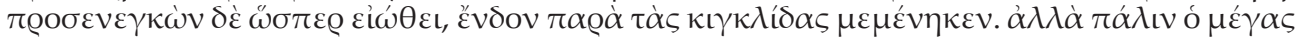

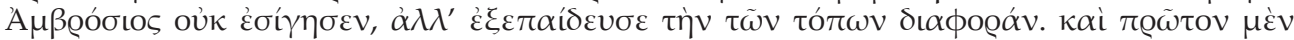

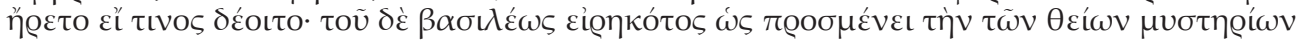


“QQué lugar correspondía al emperador en la Iglesia?”, se cuestionaba públicamente un obispo del siglo IV. Una pregunta que poco antes hubiera sido impensable no causaba mayor sorpresa. ${ }^{39} \mathrm{La}$ atmósfera que permitía semejante clase de divagaciones nos indica la profunda alteración de valores jerárquicos que se está gestando en el tejido social del Imperio. Por primera vez autoridades políticas y religiosas pueden entrar en mutua competencia desatando una pugna por el control del Estado.

Un episodio relacionado con la controversia donatista puso de manifiesto esta cuestión por primera vez. A petición de los implicados en el conflicto donatista, Constantino fue requerido como mediador e instancia decisiva en un litigio que amenazaba desgarrar la unidad de la Iglesia africana ${ }^{40}$ La reacción de Constantino a dicho requerimento tendría una repercusión trascendental. En vez de zanjar definitivamente la disputa, el emperador delegó su prerrogativa en un sínodo episcopal que emitirá primero en Roma (313) y después en Arlés (314) su veredicto. ${ }^{41}$ Posiblemente motivado por el afán de sacarse de encima un engorroso problema, el emperador, que era a la vez pontifex maximus, quedó al margen de la decisión adoptada por un grupo de expertos en la materia que, a causa de su inhibición, no tardarán en asumir las

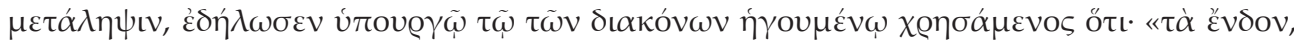

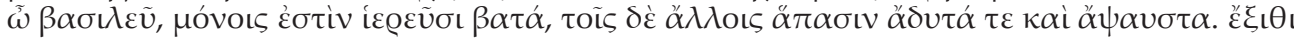

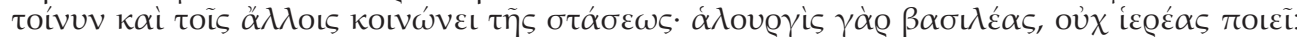
"Cuando llegó el momento de llevar las ofrendas al altar, Teodosio se levantó llorando y se aproximó al santuario. Tras realizar la ofrenda se dirigió, como era su costumbre, se quedó dentro del recinto sagrado. Una vez más Ambrosió no se quedó en silencio sino que le enseñó la importancia de distinguir cada lugar. Primero le preguntó si quería algo y cuando el emperador le replicó que esperaba recibir el santo sacramento, Ambrosio le mandó decir, por medio del primer diácono, lo siguiente: El sanctasanctórum, señor, solo está abierto para los sacerdotes; todos los demás deben permanecer afuera; apártate, pues, y quédate allí donde están los demás, que la púrpura hace emperadores, pero no sacerdotes." Véase también Sozomeno 7, 25, 9; K. Gross-ALBENhausen, Imperator christianissimus. Der christliche Kaiser bei Ambrosius und Johannes Chrysostomus, Frankfurt 1999, 99; H. Leppin, Theodosius der Große. Auf dem Weg zum christlichen Imperium, Darmstadt 2003, 138-143; 153-167.

39 Esta famosa frase atribuida a Donato ha sido recogida en la obra de Optato de Mileve, Contra Parmenianum Donatistam III 3, CSEL 26, 73.

40 Breve síntesis sobre la controversia donatista en: P. Brown, "Religious Coercion in the Later Roman Empire. The Case of North Africa", Historia 47 (1963) 283-305; L. Dossey, "Judicial Violence and the Ecclesiastical Courts in Late Antique North Africa", en: R. W. Mathisen (ed.), Law, Society and Authority in Late Antiquity, Oxford 2001, 98-114; M. Whiтвy, "Emperors and Armies, AD 235395", en: S. Swain, M. Edwards (eds.), Approaching Late Antiquity. The Transformation from Early to Late Empire, Oxford 2004, 180-184; J. FERnÁNDEZ UBIÑA, "Constantino y el triunfo del cristianismo en el Imperio romano", en: M. Sotomayor, J. Fernández Ubiña (coords.), Historia del Cristianismo, I. El mundo antiguo, Granada 2003, 348- 353; Ibid. M. V. Escribano, "El cristianismo marginado: heterodoxos, cismáticos y herejes en el s. IV", 400-417. G. GotTlieb, V. Rosenberger, Christentum und Kirche um 4. und 5. Jahrhundert, Heidelberg 2003, 30-32; E. Herrmann-Otto, Konstantin der Große, 80-93.

${ }^{41}$ Eusebio, Historia de la Iglesia 10, 5, 18-20; la carta al gobernador Anullino en Eusebio, Historia de la Iglesia 10, 7, 2; para el Concilio de Roma, Optato, contra Donatistas, 1.23-25; para el Concilio de Arlés: Optato Apéndice 4, C. Ziwsa (ed.), Optati Milevitani libri VII, CSEL, 26, 1893, 185-216.; Carta al vicario Celso: Optato Apéndice 7.34 a; K. L. NoetLichs, "Revolution from the top? <Orthodoxy> and the Persecution of Heretics in Imperial Legislation from Constantine to Justinian", en: C. Ando, J. Rüpke (eds.), Religion and Law in Classical and Christian Rome, Postdamer Altertumswissenschaftliche Beiträge, 15, 2006, 115-215. Véase también H. Lietzmann, Geschichte der Alten Kirche, Berlin 1999 (Reprint), 721-733. 
riendas de la política religiosa del Imperio. Con ello se generaba un espacio teológico con fuertes implicaciones jurídicas cada vez más independientes de las instituciones del Estado, que, de manera progresiva, conseguirá sustraerse del control del poder político. ${ }^{42}$

Constantino gozaba sin duda de un prestigio y una admiración reverencial por parte de la jerarquía eclesiástica. Gratitud y devoción son los adjetivos que caracterizan los sentimientos del clero ante el "primer emperador cristiano". Nadie le disputaba la preeminencia dentro de la cristiandad, como su cabeza visible, como inspirador de concilios y sínodos episcopales así como centro de gravedad en asuntos doctrinales: A su iniciativa y bajo su supervisión se celebrará el concilio de Nicea (325), el mayor sínodo episcopal visto hasta entonces, donde confluyeron representantes de todo el Imperio, preferentemente de Oriente ${ }^{43}$ Será Constantino quien elevará las decisiones allí adoptadas al rango de leyes. ${ }^{44}$ No menos instructiva para definir su relación con el clero cristiano es la autopercepción que tenía Constantino de su propia dignidad sacerdotal. Según Eusebio de Cesarea, se consideraba a sí mismo, y así era catalogado desde fuera, como una especie de obispo plenipotenciario. Las expresiones que nos transmite el Padre de la Iglesia al respecto episkopos ton ektos y episkopos koinos, deben ser interpretadas en un sentido maximalista y jerárquico: de todos los obispos del Imperio era Constantino el que más sobresalía, hecho que incrementaba sus atribuciones y su responsabilidad, tanto dentro como fuera de la Iglesia. ${ }^{45}$

Pero Constantino fue en muchos aspectos una excepción. Durante el reinado de sus sucesores cristianos en el trono del Imperio no sólo se consumará la progresiva inserción del emperador en la Iglesia, sino que también se nivelará su preponderancia sacerdotal que al final acabará por desaparecer. Comienza así una de las más significativas innovaciones de la época: la conquista de la esfera pública por parte de una pujante jerarquía clerical. ${ }^{46} \mathrm{La}$ ascensión de la figura del obispo irá ligada a la pérdida de competencias por parte del poder central. Las tensiones que se producen entre

42 Paulatinamente la autoridad legal será asumida por la iglesia y administrada por el obispo a través de la episcopalis audientia incluidos casos no exclusivamente eclesiásticos. Véase M. R. CIMMA, L'episcopalis audentia nelle costituzione imperiali da Costantino a Guistiniano, Turín 1989; J. D. Harries, Law and Empire in Late Antiquity, Cambridge 1998; J. D. Harries, "Resolving Disputes: The Frontiers of Law in Late Antiquity", en: R. W. Mathisen (ed.), Law, Society and Authority in Late Antiquity, Oxford 2001, 62-82.

${ }^{43}$ Cuando el emperador Constantino asistía a una asamblea conciliar era él quien la presidía. Esto no sucedió sólo en Nicea, sino también en los sínodos de Nicomedia (327) y Constantinopla (336). Véase K. M. Girardet, “Kaiser Konstantin d. Gr. Als Vorsitzender von Konzilien”, Gymnasium 98 (1991) 548-560.

${ }_{44}$ Sobre los principales puntos de debate tratados en Nicea véase R. KANY, "Kaiser Konstantin und das erste Konzil von Nizäa", en: F. Schuller, H. Wolff (eds.), Konstantin der Große. Kaiser einer Epochenwende, Lindenberg 2007, 95-124.

${ }_{45}$ Eusebio, Vida de Constantino IV 24.

${ }^{46}$ P. Brown, Die letzten Heiden, 87-138; J.H.W.G. Liebeschuetz, "The rise of bishop in the Christian Roman Empire and the Successor Kingdoms", Electrum 1 (1997) 113-125; R. LizzI, "I vescovi e i potentes della terra: Definizione e limite del ruolo episcopale nelle due partes imperii fra IV e V secolo d.C.", en: E. Rebillard, C. Sotinel (eds.), L'évêque dans la citè du IV-au Ve siècle: Image et autorité, Roma 1998; C. RApp, Holy Bishops in late Antiquity: the nature of Christian Leadership in an Age of Transition, Berkeley 2005. 
Constancio II y Atanasio de Alejandría ${ }^{47}$, o entre Teodosio y Ambrosio de Milán ${ }^{48}$, por citar los ejemplos más conocidos, son sólo las puntas visibles del iceberg.

\section{Ocaso del Imperio occidental}

Los ejemplos analizados, que ilustran un ingente proceso de disminuición del poder de los emperadores, reflejan ante todo situaciones concernientes a la parte occidental del Imperio. Será esencialmente allí, donde a la sombra de la presión de los pueblos germánicos, potentes aristocracias regionales, élites militares y renombrados obispos disputarán a la corte imperial parcelas de poder, contribuyendo así a su debilitamiento y a su progresiva desintegración. ${ }^{49}$ Esta evolución contrasta, sin embargo, con el destino de la parte oriental del Imperio, donde los emperadores consiguen defender sus fronteras y afianzar su autoridad como cabezas de la administración, del ejército y de la Iglesia.$^{50}$ Hay que resaltar en este contexto la figura de Justiniano, símbolo del poderío imperial del renovado Estado bizantino (527-565). ${ }^{51}$

Si el modelo oriental no sirvió como impulso para mantener el control sobre las provincias occidentales, eso no sólo se debió al ímpetu de las invasiones bárbaras, a todas luces más peligrosas en Occidente que en Oriente ${ }^{52}$, sino que fue también consecuencia de la crisis de poder desatada en torno al emperador, que mermaba adicionalmente su capacidad de reacción.

Cualquier intento de sistematización del material histórico analizado hasta ahora nos lleva irremediablemente a la comparación con eventos análogos, acontecidos en nuestros propios días. Todos hemos sido recientemente testigos de relevantes proce-

47 P. Barceló, Constantius II. und seine Zeit, 65 ss.; E. WiPszycKa, Storia della chiesa nella tarda antichità, Milán 2000, 146-149; C. HAAs, Alexandria in Late Antiquity, Baltimore 1997, 234-282; C. Martínez MAzA, Hipatia. La estremecedora historia de la última gran filósofa de la Antigüedad y la fascinante ciudad de Alejandría, Madrid 2009, 224-275.

${ }^{48}$ K. Gross-Albenhausen, Imperator christianissimus, 63-78; J. Gaudemet, "Droit séculier et droit de l'Église chez Ambroise", Atti del congresso internazionale di studi Ambrosiani nel XVI centenario della elevazione di Sant'Ambrogio alla catedra episcopale, Milano, 1974, Milán 1976, 286-300; S. Mazzarino, Storia sociale del vescovo Ambrogio, Roma 1989, 37-45; M. SArgenti, R.B. Bruno Siola, Normative imperiale e diritto romano negli scritti di S. Ambrogio. Epistulae-De Officiis-Orationes funebres, Milán 1991; T. Honoré, "Roman Law", en: S. Swain, M. Edwards (eds.), Approaching Late Antiquity. The transformation from Early to Late Empire, Oxford 2004, 122-124.

49 Sobre la evolución política y social de las provincias occidentales del Imperio véase J. MARTIN, Spätantike und Völkerwanderung, 37-48; P. HEATHER, Der Untergang des römischen Reiches, Stuttgart 2007, 294-493.

50 J. H. W. G. Liebeschuetz, Barbarians and Bishops. Army, Church and State in the Age of Arcadius and Chrysostom, Oxford 1990; A. CAmeron, The Later Roman Empire, Londres 1993, 40-42.

${ }_{51}$ La parte oriental del Imperio, Bizancio, se diferencia notablemente de la occidental en lo que respecta a su integridad territorial y su política religiosa, véase al respecto J. HALDON, Das Byzantinische Reich. Geschichte und Kultur eines Jahrtausends, Düsseldorf, Zürich 2002, 15-38. Sobre Justiniano véase R. Browning, Justinian and Theodora, Londres, ed. rev. 1987; J. MoorheAD, Justinian, Londres, 1994; A. Cameron, Procopius and the Sixth Century, Londres, 1985; A. Cameron, "Justin I and Justinian", The Cambridge Ancient History, vol. XIV: Late Antiquity: Empire and Successors A.D. 425600, Cambridge 2000, 63-85.

52 P. Heather, Der Untergang des römischen Reiches, 405 ss. 
sos de cambio y de transición de sistemas políticos globalizados. Basta recordar aquí el desmoronamiento del llamado Telón de Acero.

El contraste de la dinámica convulsiva que se desata en esta clase de procesos nos muestra ante todo la diferente velocidad que subyace tras el caso romano en comparación con el ejemplo actual. Mientras que el derrumbamiento del Imperio Soviético acontece en un tiempo récord, el profundo tradicionalismo inherente al sistema constitucional romano operó como factor atenuante a su favor. Por otra parte la experiencia adquirida al observar las recientes crisis nos revela cómo cualquier brusco proceso de transformación va acompañado de violencia, injusticia y inseguridad, pero también hay que constatar que no siempre deriva en desesperación, anarquía y caos generalizado.

Algo semejante parece producirse durante la fase final del Bajo Imperio, cuando las condiciones de vida de la mayoría de la población, desde antiguo precarias, no se resienten especialmente del cambio del mapa político que se genera al desintegrarse la autoridad imperial.

Recordemos que el aumento de las atribuciones judiales del praefectus praetorio en detrimento del emperador no significó el subsiguiente colapso de la administración de justicia. Posiblemente la crítica de Amiano al respecto va demasiado lejos. No podemos descartar que los afectados vieran en esta clase de medidas dirigidas a una descentralización de los procesos de decisión un efecto claramente positivo. La dislocación del poder judicial era probablemente una medida encaminada a paliar las nuevas demandas sociales..$^{53}$

También hay que reconocer que la implantación oficial de un sistema monoteísta comportó la reforma de unas instituciones desfasadas. Es difícil indagar hasta qué punto los primeros emperadores cristianos fueron conscientes de la metamorfosis que supuso la nueva orientación religiosa del Imperio. A pesar de su pérdida de protagonismo religioso como consecuencia del ascenso de una jerarquía clerical, el mismo peso de gravitación de este proceso de transformación conllevó un dinamismo social que redundó en una profunda revitalización de la esfera cultual. ${ }^{54}$

Algo parecido se puede decir de la nueva articulación de la defensa del Imperio, en la cual el incremento de las competencias de los magistri militum permitió reaccionar con eficacia ante situaciones sumamente críticas originadas en las fronteras amenazadas. Ricimero, Aetio, Estilicón u Odoacro ${ }^{55}$, pese a sus limitaciones, llevarán a cabo,

${ }_{53}$ T. Honoré, Law and the Crisis of Empire 379-455 AD: The Theodosian Dynasty and its Quaestors with a Paliggenesia of Laws of the Dynasty, Oxford 1998, 11-20; P. Porena, Le origini della preffetura del pretorio tardoantica, Roma 2003.

${ }^{54}$ Sobre la trascendencia del legado cultural cristiano en la Antigüedad tardía véase M. FuHRMAnN, Rom in der Spätantike. Porträt einer Epoche, Zürich 1994, 157-308; G. Dragon, La romanité chrétienne en Orient. Héritages et mutations, Londres 1984; P. Brown, The Rise of Western Christendom. Triumph and Diversity AD 200-1000, Cambridge 1996.

55 T. STICKLER, Aëtius: Gestaltungsspielräume eines Heermeisters im ausgehenden Weströmischen Reich, Munich 2002; T. Janssen, Stilicho. Das weströmische Reich vom Tode des Theodosius bis zur Ermordung Stilichos (395-408), Marburg 2004; A. Goltz, "Barbarische 'Kaisermacher' und das Weströmische Reich: Von Ricimer zu Odovacar", en: Rom und die Barbaren. Europa zur Zeit der Völkerwanderung, Kunst- und Ausstellungshalle der Bundesrepublik Deutschland, Munich 2008, 217 s. 
gracias a su prestigio y habilidades, una gestión que no hubiera podido ser asumida por el respectivo emperador en cada momento. ${ }^{56}$

La relación entre el emperador y su entorno es considerada transcendental por los autores antiguos a la hora de definir el difícil equilibrio entre la teoría y la praxis del ejercicio del máximo poder. En este sentido el historiador Aurelio Víctor, al evaluar la gestión de gobierno de Constancio II, no puede dejar de proferir la siguiente aseveración:

Atque uti verum absolvam brevis: ut imperatore ipso praeclarius, ita apparitorum plerisque magis atrox nihil. ${ }^{57}$

En resumen, podemos concluir que el desmontaje del poder del emperador no conllevó un agotamiento del quehacer resolutivo, sino que simplemente generó nuevas formas de concebir la gestión política y de dinamizar la filiación religiosa de la sociedad. Especialmente en la parte occidental del Imperio observamos un renacimiento de las élites militares germánicas ${ }^{58}$, de las aristocracias locales ${ }^{59}$, del Senado de Roma ${ }^{60}$ y de forma especial de la Iglesia. ${ }^{61}$ En contrapunto, la segmentación de

56 En el caso concreto de la provincia de Hispania, el general destinado a controlar y defender este territorio, Geroncio, llegó incluso a proclamar un nuevo emperador, el hispano Máximo: Sozomeno 9, 12-13; Orosio, 7, 42; P. HeAther, "The Late Roman Art of Client Management: Imperial Defence in the Fourth Century West”, en: W. Pohl, I. Wood, H. Reimitz (eds.), The Transformation of Frontiers from Late Antiquity to the Carolingians, Leiden 2001, 15-72; J. ARCE, Bárbaros y romanos en Hispania 400507 A.D., Madrid 2005.

57 Aurelio Víctor 42, 25: "Y para decir en pocas palabras la verdad: como nadie es más preclaro que el propio emperador, nadie más cruel que la mayoría de subordinados.” Traducción castellana de E. Falque, Aurelio Víctor, Libro de los Césares, Madrid-Gredos, 1999.

58 Sobre la irrupción de los godos en Occidente y la reacción de las sociedades romano-occidentales véase R. Sanz Serrano, Los Godos. Una epopeya histórica de Escandinavia a Toledo, Madrid 2009, 95-288.

59 J. F. Mathews, Western Aristocracies and Imperial Court, Oxford, 1975; F. D. GiLliard, "Senatorial Bishops in the Fourth Century", HThR, 77, 2 (1984) 153-175; R. VAN DAM, Leadership and Community in Late Antique Gaul, Berkeley, 1985; J. Drinkwater, H. Elton edd., Fifth Century Gaul: a crisis of identity?, Cambridge 1992; R.W. Mathisen, Roman Aristocrats in Barbarian Gaul: Strategies for Survival in an Age of Transition, Austin, 1993; G. AusEndA (ed.), After Empire: Towards and Ethnology of Europe's Barbarians, Woodbridge 1995.

${ }^{60} \mathrm{H}$. BLoch, "The Pagan revival in the West at the End of the Fourth Century", en: A. Momigliano (ed.), The conflict between Paganism and Christianity in the Fourth Century, Oxford 1963, 193-218; M. T. W. ArNheIm, The Senatorial aristocracy in the Later Roman Empire, Oxford 1972; F. CANFORA, Simmaco, Ambrogio, L'altare della Vittoria, Palermo 1991; B. LAnçon, Rome dans l'Antiquité tardive 312-604 après J.-C., París 1995, 83-104. D. Schlinkert, "Dem Kaiser folgen. Kaiser, Senatsadel und höfische Funktionselite (comites consistoriani) von der "Tetrarchie" Diokletians bis zum Ende der konstantinischen Dynastie", en: A. Winterling (ed.), Comitatus. Beiträge zur Erforschung des spätantiken Kaiserhofes, Berlin 1998, 133-159.

${ }^{61}$ G. W. Bowersock, "From Emperor to Bishop: the Shelf-Conscious Transformation of Political Power in the Fourth century A.D.", CP 81 (1986) 298-307; A. DEMANDT, "Grenzen spätrömischer Staatsgewalt”, en: F. Paschoud, J. Szidat (eds.), Usurpationen in der Spätantike, Stuttgart 1997, 155163; M. R. Salzman, The Making of a Christian Aristocracy. Social and Religious Change in the Western Roman Empire, Cambridge (Massachusetts) 2002; R. van DAM, "Bishops and Society", en: A. Casiday, F. W. Norris (eds.), The Cambridge History of Christianit, Vol. 2, Constantine to c. 600, Cambridge 2007, 343-366. 
poderes y el cada vez más visible desmantelamiento de la capacidad gubernamental del emperador acentuarán irremediablemente su superfluidad. Si el emperador no era ya necesario, ¿qué futuro se podía augurar al Imperio?

Amiano Marcelino, historiador de la época teodosiana, no era el único intelectual de su generación que contemplaba con creciente preocupación el devenir, como manifiesta en un conocido párrafo de su obra, donde se reflexiona sobre la función civilizadora de Roma a lo largo de su historia:

In iuvenem erectus et virum ex omni plaga, quam orbis ambit immensus, reportauit laureas et triumphos; iamque uergens in senium et nomine solo aliquotiens uincens ad tranquilliora uitae discessit. Ideo urbs uenerabilis post suberbas efferatarum gentium ceruices oppresseas latasque leges fundamenta libertatis et retinacula sempiterna uelut frugi parens et prudens et diues Caesaribus tamquam liberis suis regenda patrimonii iura permisit. ${ }^{2}$

Las sentidas palabras de Amiano no pueden ocultar la esperanza de que un emperador providencial contribuyera notablemente a la regeneración del Estado. Es de suponer que estas ideas las compartía con buena parte de sus contemporáneos. Sin embargo, semejante visión determinista de la historia, alimentada por la convicción de la insustituibilidad del gobierno imperial, no ponía remedio a la manifiesta insostenibilidad del sistema propagado.

Probablemente Amiano publicó su obra en el reinado de Teodosio. Si lo hubiera hecho durante el gobierno de sus sucesores, Arcadio (395-408) y Honorio (395-423), su veredicto sobre las perspectivas de futuro habría sido con seguridad bastante menos risueño. Para caracterizar a estos emperadores sirve la famosa frase procedente de la teoría política moderna: le roi règne, et il ne gouverne pas. En estas circunstancias era a la larga imposible mantener un ente estatal articulado en torno al emperador.

El epílogo de este proceso lo constituye la recepción de la destitución del último emperador de Occidente. En el liber pontificalis no se consigna ni tan siquiera una mínima mención del transcendental año 476 en el que se produce la caida de Rómulo Augústulo a instancias del magister militum Odoacro, insertada dentro del pontificado del papa Simplicio (468-483). La definitiva deposición del emperador de Oc-

${ }^{62}$ Amiano Marcelino 14, 6, 4-5. "Llegada ya la juventud y la madurez, de todas las zonas que comprende el vasto mundo se trajo laureles y triunfos y, ya que los comienzos de la vejez, venciendo a veces tan sólo gracias a su fama, se retiró a una vida más tranquila. Por eso esta ciudad venerable, después de someter las cabezas soberbias de los pueblos más fieros, de darles leyes, fundamentos y garantías eternas de libertad, a la manera de un padre frugal, prudente y rico, entregó a los Césares como si fueran sus hijos, el derecho de regir su patrimonio." Traducción castellana de M. L. Harto Trujillo, Amiano Marcelino, Historia, Madrid, Akal, 2002. Sobre la ideologia imperial F. KoLB, Herrscherideologie in der Spätantike, Berlin 2001. Sobre el concepto del tiempo y de las épocas en la Antigüedad tardía véase los artículos recogidos en: L. DE SALVo, A. Sindoni, Tempo sacro e tempo profano. Visione laica e visione cristiana del tempo e della storia, Soveria Mannelli 2002; A. DI BERARdino, "Tempo sociale pagano e cristiano nel IV secolo", en: A. Saggioro (ed.), Diritto romano e identità cristiana. Definizioni storico-religiose e confronti interdisciplinari, Roma 2005, 95-121; C. MARTíneZ MAZA, "Los primeros calendarios cristianos", en: J. Martínez-Pinna (ed.), Initia Rerum. Sobre el concepto del origen en el mundo antiguo. Thema 49, Málaga, 2006, 209-228. 
cidente parecía tan lógica y poco interesante que el cronista no creyó que tal suceso mereciera ser retenido en sus apuntes. ${ }^{63}$

Salvando los diferentes matices, este es también el tenor de la selección de las fuentes consultadas a través de las cuales hemos podido extraer algunas informaciones separadas, que, puestas conjuntamente a colación, nos muestran un sistema de coordenadas que certifica la pérdida de las atribuciones religiosas, judiciales y militares del emperador. Sin embargo, y a pesar de su indudable evidencia, ningún autor antiguo se cuestiona explícitamente las implicaciones de este fenómeno.

El hecho de tener que reconstruirlo nosotros punto por punto, y si cabe de forma sistemática, desde una perspectiva retrospectiva para poder llegar a las conclusiones expuestas, no implica que los círculos intelectuales del Bajo Imperio no fueran conscientes de ello, pero sí dice bastante sobre su fijación obsesiva en la inalteraridad de los modelos del pasado. Este estado de relativa "inconsciencia" también puede ser extendido a aquellos autores que enfocan la última fase de la historia de Roma desde un prisma partidista, de tinte religioso. Orosio y Zósimo son dos ejemplos significativos de ello.

63 J. Martin, Spätantike und Völkerwanderung, 48. 